\title{
Accurate calculations of second-order electric and magnetic properties: Two ways of physically justified modifications of basis sets
}

ARTICLE in CHEMICAL PHYSICS · JUNE 2010

Impact Factor: 1.65 · DOI: 10.1016/j.chemphys.2010.04.033

CITATIONS

3

5 AUTHORS, INCLUDING:

Sergiy I Okovytyy

Dnepropetrovsk National University

49 PUBLICATIONS 215 CITATIONS

SEE PROFILE
READS

18 
Provided for non-commercial research and education use. Not for reproduction, distribution or commercial use.

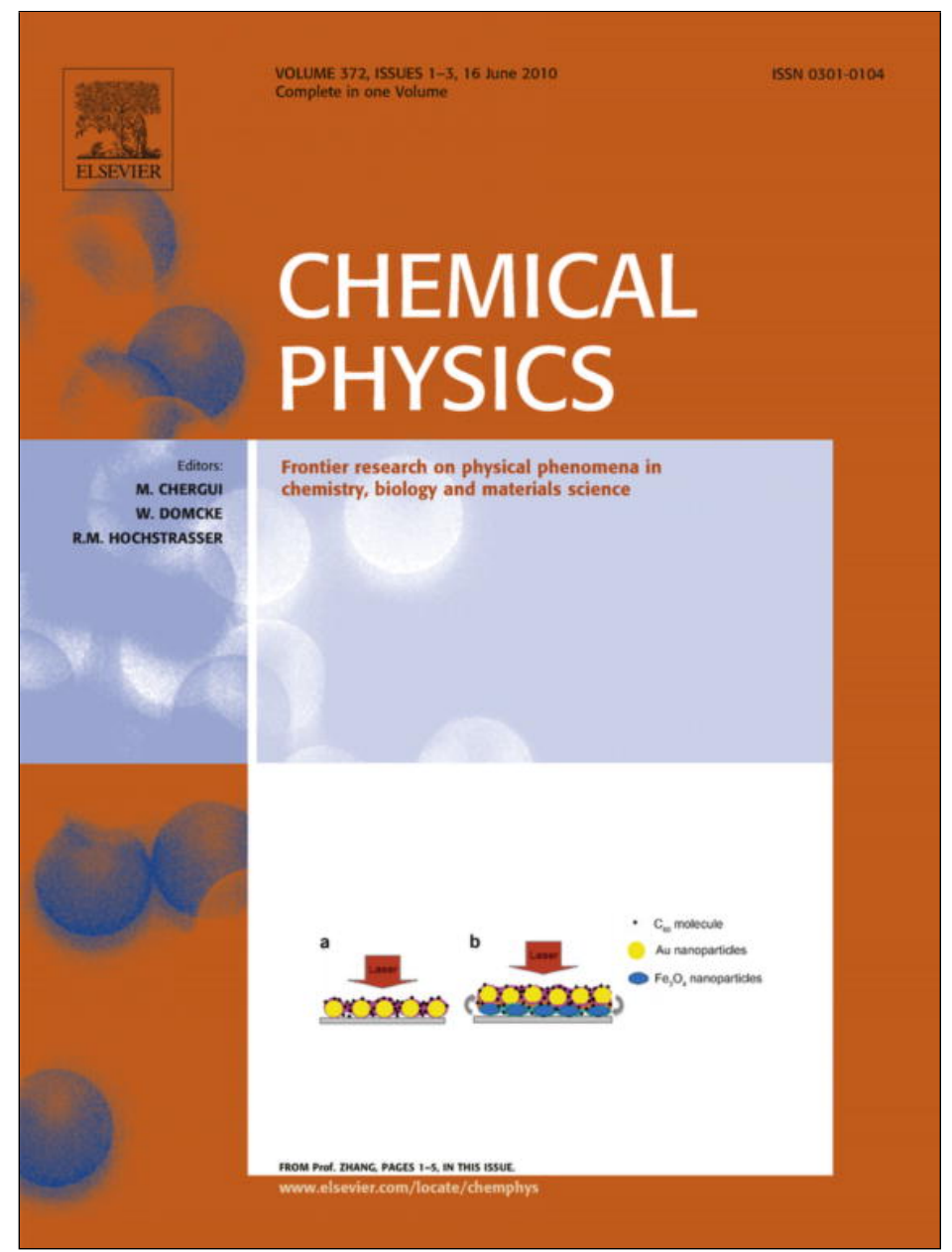

This article appeared in a journal published by Elsevier. The attached copy is furnished to the author for internal non-commercial research and education use, including for instruction at the authors institution and sharing with colleagues.

Other uses, including reproduction and distribution, or selling or licensing copies, or posting to personal, institutional or third party websites are prohibited.

In most cases authors are permitted to post their version of the article (e.g. in Word or Tex form) to their personal website or institutional repository. Authors requiring further information regarding Elsevier's archiving and manuscript policies are encouraged to visit:

http://www.elsevier.com/copyright 


\title{
Accurate calculations of second-order electric and magnetic properties: Two ways of physically justified modifications of basis sets
}

\author{
V. Bolshakov ${ }^{\text {a }}$, V. Rossikhin ${ }^{\mathrm{a}, *}$, E. Voronkov ${ }^{\mathrm{b}}$, S. Okovytyy ${ }^{\mathrm{c}}$, J. Leszczynski $^{\mathrm{d}}$ \\ ${ }^{a}$ Pridneprovs'ka State Academy of Civil Engineering and Architecture, Dnepropetrovsk, Ukraine \\ ${ }^{\mathrm{b}}$ Dnepropetrovsk National University of Railway Transport, Dnepropetrovsk, Ukraine \\ ${ }^{\mathrm{c}}$ Dnepropetrovsk National University, named after Oles Gonchar, Dnepropetrovsk, Ukraine \\ d Jackson State University, Jackson, MS, USA
}

\section{A R T I C L E I N F O}

\section{Article history:}

Received 12 February 2010

In final form 28 April 2010

Available online 4 May 2010

\section{Keywords:}

Polarizability

Magnetizability

Nuclear magnetic shielding

Ab initio

Basis set

\begin{abstract}
A B S T R A C T
Second-order electric and magnetic properties calculated using an approach based upon the simultaneous analytical dependence of the bond order matrix and basis set functions on the corresponding perturbation parameters have been obtained and analyzed for a series of organic molecules. Various methods of selection of basis set quality for different atoms in investigated molecules were examined in conjunction with calculations of ${ }^{1} \mathrm{H}$ NMR chemical shifts. Comparison of the results obtained at different levels of theory (HF, DFT, MP2) demonstrates small correlation effects for polarizability and magnetic susceptibility while the electron correlation effects play crucial role for calculations of nuclear magnetic shielding (chemical shifts).
\end{abstract}

(C) 2010 Elsevier B.V. All rights reserved.

\section{Introduction}

Understanding of the characteristics of various physico-chemical properties of molecules could be acquired based on their important second-order properties such as polarizability, magnetizability and nuclear magnetic shielding. In addition to numerous experimental investigations of electric and magnetic properties of chemical compounds in recent years the theoretical, quantum mechanical methods become a useful and popular tools both for prediction a variety of properties for new compounds and for structure elucidation and signal assignments based on combined experimental and theoretical investigation of NMR spectra.

The exact calculation of the physical properties of many-body systems using the quantum mechanical formalism rests first of all on the many-electron problem difficulties. Such problems can be avoided using designated, approximate methods. One of the most widespread methods of the electronic wave function calculations is coupled-perturbed-Hartree-Fock (CPHF) approach. Since in the conventional CPHF method [1] a common gauge origin is adopted for all molecular orbitals (MO) thus implying a poor description for nearly all atoms in a molecule [2], in order to avoid gauge origin problem a number of approaches have derived from CPHF for calculations of second-order magnetic properties. The

\footnotetext{
* Corresponding author.

E-mail address: vvr375@gmail.com (V. Rossikhin).
}

most popular among them are: GIAO [3], IGLO [4,5], LORG [6], IGAIM [7], CSGT [8] methods. Some of these methods have been extended later to DFT [9], MP2 [10,11] and other correlated formalisms (see the discussion by Helgaker et al. [12]). Nevertheless, due to the approximate solution of the corresponding equations, the wave function does not provide a true description of electronic density distribution in all domains of the configuration space. The well known solution to this problem is an "extension" of the initial basis set of atomic orbitals (AO) used in calculations. A traditional way of such an "extension" is the increase of the numbers of original AOs by means of augmentation of the so-called polarization and diffuses functions to the initial set of atomic orbitals. However, in such a case, the size of the basis set obtained exceeds considerably the initial basis set size. In addition, neither the required quantity nor the functional form of the additional functions is defined by any physically justified manner.

In this paper the method of selection of the physically justified basis sets is proposed. The considered basis sets of AO's are characterized by relatively small sizes and the most accurate description of the wave function behavior in the configuration space domains that provide noticeable contribution to the value of evaluated physical property. This is of a crucial importance for study of behavior of a system subjected to the influence of an external field where the problem of determining the "distortion" in the original basis set arises. The procedure to construct such kind of basis set (designated earlier as $6-31 \mathrm{G}^{\# \#}$ ) is shortly described. In order to evaluate reliability of the proposed basis set the test calculations 
of polarizabilities, magnetic susceptibilities and hydrogen chemical shifts for the series of organic molecules have been performed and compared with experimental values as well as the results of calculations at various levels of theory.

\section{Theory}

In the proposed here approximation the expressions for the second-order correction $E^{(2)}$ to the energy of unperturbed molecule $E^{(0)}$ are computed as

$E^{(2)}=2 S p\left[P^{(1)} W_{1}^{(0,0)}+P^{(0)}\left(W_{1}^{(1,0)}+W_{1}^{(0,1)}\right)+P^{(0)} W_{2}^{(0,0)}\right]$

Here $W_{i}^{(n, m)}(i=1,2 ; n, m=0,1)$ is the matrix with matrix elements $W_{i p q}^{(n, m)}=\left\langle\chi_{p}^{(n)}, W_{i} \chi_{q}^{(m)}\right\rangle, W_{i}$ corresponds to the property perturbation operator; $\chi_{p}^{(1)}$ is the first-order correction function to the initial basis function $\chi_{p}^{(0)}$.

All formulae are written in the atomic units: $h=m=e=1$.

An explicit expression for the first-order density (bond order) matrix $P^{(1)}$ to the zero-order matrix $P^{(0)}$ given below has been derived in [13]:

$P^{(1)}=\sum_{a=1}^{n} \sum_{b=n+1}^{m}\left(C_{b}^{(0)} K_{b a} \widetilde{C}_{a}^{(0)}+C_{a}^{(0)} \widetilde{K}_{b a} \widetilde{C}_{b}^{(0)}\right)-S^{-1} \tilde{\mu} P^{(0)}-P^{(0)} \mu S^{-1}$

where $K_{b a}=\left(\varepsilon_{a}-\varepsilon_{b}\right)^{-1}\left[\widetilde{C}_{b}^{(0)}\left(F^{(1)}-\varepsilon_{a} \tilde{\mu}-\varepsilon_{b} \mu\right) C_{a}^{(0)}\right], \varepsilon_{a}$ are one-electron energies; $F^{(1)}$ is the first-order correction to the Fock operator matrix; $\mu$ is the matrix with elements $\mu_{p q}^{(n, m)}=\left\langle\chi_{p}^{(n)}, \chi_{q}^{(m)}\right\rangle ; S^{-1}$ represents the matrix reverse to an overlap matrix $S ; C_{a}^{(0)}$ is the molecular orbital expansion coefficient.

By substituting (2) into (1) one can obtain:

$$
\begin{aligned}
E^{(2)}= & 2 S p\left[\sum_{a=1}^{n} \sum_{b=n+1}^{m}\left(C_{b}^{(0)} K_{b a} \widetilde{C}_{a}^{(0)}+C_{a}^{(0)} \widetilde{K}_{b a} \widetilde{C}_{b}^{(0)}\right) W_{1}^{(0,0)}\right. \\
& +P^{(0)}\left(W_{1}^{(1,0)}+W_{1}^{(0,1)}\right)-\left(S^{-1} \mu P^{(0)}+P^{(0)} \mu S^{-1}\right) W_{1}^{(0,0)} \\
& \left.+P^{(0)} W_{2}^{(0,0)}\right]
\end{aligned}
$$

here the first term appears in the case of an unperturbed basis; the second term expresses the basis set dependence on perturbation; the third one takes into account complex dependence of the first-order bond order matrix $P^{(1)}$ on the perturbation parameter $\lambda$ [i.e., $\left.P^{(1)}=f(\lambda, \chi(\lambda))\right]$ and the fourth term describes the second order dependence on parameter $\lambda$ in Hamiltonian (in the magnetic field case).

If $\chi^{(1)}$ is zero, then the expressions for $P^{(1)}$ and $E^{(2)}$ are reduced to the form arising from the standard perturbation theory that is used in almost all software packages for calculation of molecular properties.

Determination of explicit form of the first-order correction functions $\chi^{(1)}$ to the basis set AO's $\chi^{(0)}$ is based upon the solution of inhomogeneous Schrödinger equation:

$$
\left[-\frac{1}{2} \Delta+V(r)-E\right] \chi(r)=\lambda W(r) \chi(r)
$$

where $V(r)$ is a potential which defines the form of basis set AO's and $W(r)$ is the perturbation operator. The differential equation (4) can be reduced to the integral equation of the second order.
From its solution it follows that the first-order correction to the solution $\chi^{(0)}(r)$ which corresponds to the homogeneous form $(\lambda W(r) \equiv 0)$ of Eq. (4) is determined by relation:

$\chi^{(1)}(r)=\int G_{E}\left(r, r^{\prime}\right) W\left(r^{\prime}\right) \chi^{(0)}\left(r^{\prime}\right) d r^{\prime}$

here $G_{E}\left(r, r^{\prime}\right)$ is the Green's function of the homogeneous Schrödinger equation. For the spherically symmetrical potential $V(r)$ the Green's function can be expressed in the following form:

$G_{E}\left(r, r^{\prime}\right)=\sum_{l, m} g_{l}\left(r, r^{\prime} ; E\right) Y_{l m}\left(r_{0}\right) Y_{l m}^{*}\left(r_{0}^{\prime}\right)$

where $Y_{l m}$ are spherical functions of the argument $r_{0}=r / r$, and $g_{l}$ $\left(r, r^{\prime} ; E\right)$ represents part of the Green's function.

In molecular calculations the Gaussian-type functions are the most commonly used as the basis set functions:

$\chi(n, l, m)=N_{n} r^{n-1} \exp \left(-\xi r^{2}\right) Y_{l m}\left(r_{0}\right)$

Such functions are eigenfunctions of an operator that approximates to form given by (4) the homogeneous equations with the potentials:

$V(r)=2 \xi^{2} r^{2}+\frac{A}{2 r^{2}}$

where $A=n(n-1)-l(l+1), \xi$ is an orbital exponent, and $N_{n}$ is a normalization factor. With this form of $A$ the Gaussian-type functions contain only the nodeless functions and they do not form the complete basis set, as long as they are the solutions of the Schrödinger equation with different potentials of type (8).

The analytical representation of the radial Green function for potentials (8) could be written through the Whittaker functions [14].

In the case of perturbation by weak homogeneous electric field the parameters of perturbation represent the components $d_{x}, d_{y}, d_{z}$ of dipole moment operator $\hat{d}$.

According to (5) the expressions for the first-order correction functions to the Gaussian type basis functions in electric field $\left(W_{1}=d_{z}=-r \cos \theta\right.$ in a.u. ) could be written as follows:

$$
\begin{aligned}
& S^{(1)}=-\frac{N_{1}}{2 \xi_{1} \sqrt{3}} r e^{-\xi_{1} r^{2}} Y_{10} \\
& P_{x, y}^{(1)}=-\frac{N_{2}}{2 \xi_{2} \sqrt{5}} r^{2} e^{-\xi_{2} r^{2}}\left\{\begin{array}{c}
Y_{21}^{c} \\
Y_{21}^{s}
\end{array}\right\} \\
& P_{z}^{(1)}=-\frac{N_{2} \sqrt{3}}{\xi_{2}} e^{-\xi_{2} r^{2}}\left\{\frac{\sqrt{\pi}}{3} r^{2}\left[Y_{10}\right]^{2}-\frac{1}{4 \xi_{2}} Y_{00}\right\}
\end{aligned}
$$

Correction functions $\chi^{(1)}$, which correspond to perturbation operators $d_{x}$ and $d_{y}$, could be expressed in a form similar to (9).

In the case of perturbation by weak homogeneous magnetic field perturbation operator $\widehat{W}_{1}$ depends on the choice of the origin coordinate system for the vector potential and could be expressed as follows:

$W_{1}=(1 / 2 c) \cdot(\vec{r}-\vec{R}) \times \nabla=W_{0}-(1 / 2 c) \cdot \vec{R} \times \nabla$

where $\vec{r}$ is the electron position vector relative to a nucleus, and $\vec{R}$ is the nucleus position vector relative to the molecular reference system. Since the effect of the $W_{0}$ operator on the basis function $\chi^{(0)}$ is reduced to the modification of the magnetic quantum number $m$, the contribution of this operator to (5) vanishes. Thus the operator $-(1 / 2 c) \cdot \vec{R} \times \nabla$ could be suitable for the description of a perturbation.

The first-order correction functions to Gaussian orbitals of S-, $\mathrm{P}-$, and D-type in homogeneous magnetic field obtained using operator $L_{x x}=[(r-R) \partial / \partial r]_{x x}$ could be written as: 


$$
\begin{aligned}
S^{(1)}= & -N_{1} \frac{r e^{-\xi r^{2}}}{\sqrt{3}}\left(R_{z} Y_{11}^{s}-R_{y} Y_{10}\right) \\
P_{x}^{(1)}= & N_{2} \frac{r^{2} e^{\xi r^{2}}}{\sqrt{5}}\left(R_{y} Y_{21}^{c}-R_{z} Y_{22}^{c}\right) \\
P_{y}^{(1)}= & N_{2} r^{2} e^{-\xi r^{2}}\left[R_{z}\left(\frac{Y_{22}^{c}}{\sqrt{5}}+\frac{Y_{20}}{\sqrt{15}}-\frac{Y_{00}}{\sqrt{3}}\right)+R_{y} \frac{Y_{21}^{s}}{\sqrt{5}}\right] \\
P_{z}^{(1)}= & N_{2} r^{2} e^{-\xi r^{2}}\left[R_{y}\left(\frac{Y_{00}}{\sqrt{3}}+\frac{2 Y_{20}}{\sqrt{15}}\right)-R_{z} \frac{Y_{21}^{s}}{\sqrt{5}}\right] \\
D_{0}^{(1)}= & N_{3} r^{3} e^{-\xi r^{2}}\left[R_{y}\left(\frac{3 Y_{30}}{\sqrt{35}}+\frac{2 Y_{10}}{\sqrt{15}}\right)-R_{z}\left(\sqrt{\frac{6}{35}} Y_{31}^{s}-\frac{Y_{11}^{s}}{\sqrt{15}}\right)\right] \\
D_{1}^{(1)}= & N_{3} r^{3} e^{-\xi r^{2}}\left[R_{y}\left(\frac{4 Y_{31}^{c}}{\sqrt{70}}+\frac{2 Y_{11}^{c}}{\sqrt{5}}\right)-R_{z} \frac{Y_{32}^{s}}{\sqrt{7}}\right] \\
D_{-1}^{(1)}= & -N_{3} \frac{r e^{-\xi r^{2}}}{2 \xi} R_{z} \cdot 2 \sqrt{5} Y_{10}+N_{3} r^{3} e^{-\xi r^{2}} \\
& \times\left[R_{y}\left(\frac{Y_{32}^{c}}{\sqrt{7}}+\frac{3 Y_{30}}{\sqrt{105}}+\frac{Y_{10}}{\sqrt{5}}\right)+R_{y}\left(+\frac{4 Y_{31}^{s}}{\sqrt{70}}+\frac{Y_{11}^{s}}{\sqrt{5}}\right)\right] \\
D_{2}^{(1)}= & -N_{3} r^{3} e^{-\xi r^{2}}\left[R_{z}\left(\frac{3 Y_{33}^{s}}{\sqrt{42}}+\frac{Y_{31}^{s}}{\sqrt{70}}-\frac{Y_{11}^{s}}{\sqrt{5}}\right)-R_{y} \frac{Y_{32}^{s}}{\sqrt{7}}\right] \\
D_{-2}^{(1)}= & N_{3} r^{3} e^{-\xi r^{2}}\left[R_{z}\left(\frac{3 Y_{33}^{c}}{\sqrt{42}}+\frac{Y_{31}^{c}}{\sqrt{70}}-\frac{Y_{11}^{c}}{\sqrt{5}}\right)+R_{y} \frac{Y_{32}^{s}}{\sqrt{7}}\right]
\end{aligned}
$$

where $Y_{l m}^{c}$ and $Y_{l m}^{s}$ represent real spherical functions, and $R_{x, y, z}$ are components of radius-vector of nucleus relatively to molecular system coordinates. Corresponding expressions for $L_{y y}$ and $L_{z z}$ perturbation operators could be obtained from (10) using cyclic permutation procedure.

Based on expressions (1), (2), (3), (9), and (10) we have developed computational program POLMAG-3, which allows accurate prediction of static polarizability and magnetic susceptibility at the Hartree-Fock level of theory using minimal 6-31G basis set (see $[15,16]$ and Table 1 ).

An alternative way to improve accuracy of predictions for second-order electric and magnetic properties is augmentation of the standard $6-31 \mathrm{G}$ basis set. It can be accomplished by adding polarization and diffuses functions and expanding them in a series of basis-like functions obtained from expressions (9), (10).

As could be seen from Eqs. (9) and (10), corrections to be applied in electric and magnetic field include electron radius-vector at the same power as applicable for basis functions augmented by an equal set of spherical functions. Taking into account contributions of all perturbation operator components, correction $\chi^{(1)}$ could be expressed as expansion in a series of the set of atomic orbitals that are the same type as the orbitals in unperturbed basis set, following (11):

$$
\begin{aligned}
& S^{(1)}(\xi) \rightarrow P^{(0)}(\xi) \\
& P^{(1)}(\xi) \rightarrow S^{(0)}(\xi)+d^{(0)}(\xi) \\
& D^{(1)}(\xi) \rightarrow p^{(0)}(\xi)+f^{(0)}(\xi)
\end{aligned}
$$

Augmentation of 6-31G basis set by physically justified additional functions leads to formation of $6-31 \mathrm{G}^{\# \#}$ basis set which could be expressed in the following form $[13,17,18]$ :

$$
\begin{aligned}
& \left\{S\left(\xi_{1}\right), S P\left(\xi_{2}\right), S P\left(\xi_{3}\right), S P\left(\xi_{4}\right), S P\left(\xi_{5}\right), D\left(\xi_{6}\right), D\left(\xi_{7}\right)\right\} \\
& \quad+\left\{p\left(\xi_{1}\right), d\left(\xi_{2}\right), d\left(\xi_{3}\right), d\left(\xi_{4}\right), d\left(\xi_{5}\right), p\left(\xi_{6}\right), p\left(\xi_{7}\right) f\left(\xi_{6}\right), f\left(\xi_{7}\right)\right\}
\end{aligned}
$$

Thus new 6-31G $\mathrm{G}^{\# \#}$ basis set does not have uncertainties in selection of additional basis functions and could be used for calculations of both the electric and magnetic properties in combination with any DFT or $a b$ initio approach. In addition, the inclusion of our recommended basis set does not require program code modification.

\section{Results and discussion}

Table 1 illustrates the performance of a recently developed POLMAG-3 program using the 6-31G basis set for predictions of the static polarizability for a number of compounds. It also includes comparison with the results of standard coupled-perturbed

\begin{tabular}{|c|c|c|c|c|c|c|c|c|c|c|c|c|c|}
\hline \multirow[t]{2}{*}{ Molecule } & \multirow{2}{*}{$\begin{array}{l}\text { POLMAG } \\
6-31 \mathrm{G} \\
\mathrm{HF}\end{array}$} & \multirow{2}{*}{$\begin{array}{l}\text { Gaussian } \\
6-31 G \\
\text { HF }\end{array}$} & \multicolumn{5}{|c|}{ Gaussian 6-31G"\#\# } & \multicolumn{5}{|c|}{ Gaussian 6-31G(2df,p) } & \multirow{2}{*}{$\begin{array}{l}\text { Expt. } \\
{[20,21]}\end{array}$} \\
\hline & & & $\mathrm{HF}$ & MP2 & BP86 & B3LYP & PBE1PBE & $\mathrm{HF}$ & MP2 & BP86 & B3LYP & PBE1PBE & \\
\hline $\mathrm{CH}_{4}$ & 16.72 & 11.98 & 15.19 & 15.66 & 16.63 & 15.96 & 15.88 & 12.94 & 12.86 & 13.63 & 13.21 & 13.48 & 16.52 \\
\hline $\mathrm{HC} \equiv \mathrm{CH}$ & 23.27 & 13.69 & 19.91 & 19.90 & 20.81 & 20.15 & 20.24 & 16.15 & 15.83 & 16.67 & 16.28 & 16.38 & 23.53 \\
\hline $\mathrm{H}_{2} \mathrm{C}=\mathrm{CH}_{2}$ & 27.49 & 19.60 & 24.94 & 24.65 & 26.04 & 25.23 & 25.18 & 21.33 & 20.52 & 21.91 & 21.37 & 21.72 & 28.26 \\
\hline $\mathrm{H}_{3} \mathrm{C}-\mathrm{CH}_{3}$ & 28.61 & 22.22 & 26.12 & 27.07 & 28.78 & 27.59 & 27.39 & 23.25 & 23.24 & 24.77 & 23.94 & 24.50 & 28.52 \\
\hline $\mathrm{HC} \equiv \mathrm{C}-\mathrm{CH}_{3}$ & 41.27 & 24.94 & 31.98 & 32.69 & 35.05 & 33.59 & 33.53 & 27.62 & 27.64 & 29.85 & 28.79 & 29.66 & 41.76 \\
\hline cyclo- $\mathrm{C}_{3} \mathrm{H}_{6}$ & 35.74 & 28.71 & 33.08 & 34.39 & 36.17 & 34.77 & 34.48 & 29.98 & 30.03 & 31.84 & 33.08 & 33.88 & 38.06 \\
\hline $\mathrm{H}_{3} \mathrm{C}-\mathrm{CH}_{2}-\mathrm{CH}_{3}$ & 40.92 & 32.23 & 37.07 & 38.56 & 41.06 & 39.31 & 39.02 & 33.47 & 33.63 & 36.04 & 34.75 & 35.66 & 39.96 \\
\hline 1-Butyne & 50.71 & 35.53 & 43.30 & 43.57 & 47.76 & 45.73 & 45.51 & 38.32 & 38.50 & 41.64 & 40.10 & 41.32 & 50.07 \\
\hline 1-Butene & 53.05 & 40.88 & 47.85 & 48.65 & 52.08 & 50.01 & 49.68 & 42.95 & 42.45 & 45.99 & 44.42 & 45.56 & 53.85 \\
\hline trans-2-Butene & 53.22 & 41.59 & 48.46 & 49.33 & 53.31 & 51.04 & 50.71 & 43.69 & 43.24 & 47.23 & 45.44 & 45.34 & 57.36 \\
\hline $\mathrm{C}_{6} \mathrm{H}_{6}$ & 73.78 & 51.10 & 62.11 & 64.01 & 66.20 & 64.11 & 63.79 & 55.35 & 56.21 & 59.02 & 57.29 & 58.59 & 67.57 \\
\hline cyclo- $\mathrm{C}_{6} \mathrm{H}_{12}$ & 74.15 & 57.26 & 64.49 & 67.31 & 71.07 & 68.20 & 67.54 & 59.53 & 60.41 & 64.67 & 62.99 & 64.80 & 74.32 \\
\hline $\mathrm{CH}_{3} \mathrm{OH}$ & 20.13 & 14.21 & 18.22 & 19.49 & 20.82 & 19.83 & 19.63 & 16.00 & 16.48 & 17.67 & 16.97 & 16.90 & 20.79 \\
\hline $\mathrm{CH}_{3} \mathrm{CHO}$ & 29.42 & 21.96 & 25.94 & 27.55 & 29.44 & 28.00 & 27.78 & 23.64 & 24.41 & 26.25 & 25.11 & 25.04 & 28.87 \\
\hline $\mathrm{CH}_{3} \mathrm{CH}_{2} \mathrm{OH}$ & 32.17 & 24.44 & 29.23 & 31.07 & 33.25 & 31.67 & 31.34 & 26.32 & 26.98 & 29.05 & 27.87 & 27.74 & 34.50 \\
\hline MAE & 1.471 & 10.907 & 5.070 & 4.003 & 1.974 & 3.250 & 3.483 & 8.893 & 8.767 & 6.514 & 7.489 & 6.891 & \\
\hline RMSE & 2.274 & 2.782 & 2.038 & 2.295 & 2.012 & 2.012 & 1.966 & 2.292 & 2.548 & 2.351 & 2.455 & 2.509 & \\
\hline$A$ & 0.964 & 1.248 & 1.126 & 1.092 & 1.038 & 1.078 & 1.087 & 1.212 & 1.194 & 1.118 & 1.150 & 1.116 & \\
\hline B & 1.546 & 3.624 & 0.635 & 0.683 & 0.223 & 0.373 & 0.272 & 2.249 & 2.647 & 2.538 & 2.557 & 3.019 & \\
\hline$R$ & 0.9919 & 0.9878 & 0.9935 & 0.9917 & 0.9936 & 0.9936 & 0.9939 & 0.9917 & 0.9898 & 0.9913 & 0.9905 & 0.9901 & \\
\hline
\end{tabular}
calculations at HF, DFT and MP2 levels with proposed here 6-31G"\# and standard 6-31G(2df,p) basis sets. Geometrical parameters of all considered species have been optimized at the same levels of theory. Standard coupled-perturbed calculations have been carried out with the Gaussian 03 software [19].

A comparison of the calculated and experimental values clearly demonstrates the superiority of the POLMAG/6-31G calculations over the standard CPHF computations with both the 6-31G, and also with the extended 6-31G(2df,p) basis sets. The electron correlation effects considered at the DFT and MP2 levels do not lead to considerable improvement of accuracy of calculations with

Table 1

Calculated and experimental isotropic polarizability(in a.u.) for row of organic compounds, values of MAE and RMSE, and parameters of the linear regression equation $\lambda_{\text {expt }}=A \lambda_{\text {calc }}+B$. 
6-31G(2df,p) basis set. In contrast, an application of 6-31G"\# basis set which has the same number, but different (physically justified) types of the additional functions allows one to obtain values which are in good correspondence with the experimental results. Linear regression analysis shows that among the used approaches the BP86/6-31G ${ }^{\# \# ~ l e v e l ~ p r o v i d e s ~ r e s u l t s ~ t h a t ~ a r e ~ c h a r a c t e r i z e d ~ b y ~ t h e ~}$

Table 2

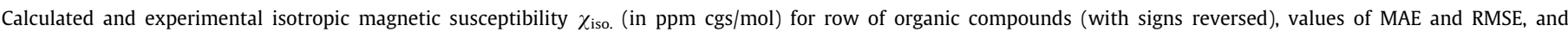
parameters of the linear regression equation $\chi_{\text {expt }}=A \chi_{\text {calc }}+B$.

\begin{tabular}{|c|c|c|c|c|c|c|c|c|c|c|c|c|}
\hline \multirow[t]{2}{*}{ Molecule } & \multicolumn{2}{|l|}{$\begin{array}{l}\mathrm{HF} \\
6-31 \mathrm{G}\end{array}$} & \multicolumn{2}{|l|}{$\begin{array}{l}\mathrm{HF} \\
6-31 \mathrm{G}^{\# \#}\end{array}$} & \multicolumn{2}{|l|}{ BP86 } & \multicolumn{2}{|l|}{ B3LYP } & \multicolumn{2}{|l|}{ PBE1PBE } & \multirow[t]{2}{*}{$\begin{array}{l}\text { GIAO/BP86/ } \\
6-31 G(2 d f, p)\end{array}$} & \multirow[t]{2}{*}{ Expt. $[20,21]$} \\
\hline & GIAO & CSGT & GIAO & CSGT & GIAO & CSGT & GIAO & CSGT & GIAO & CSGT & & \\
\hline $\mathrm{CH}_{4}$ & 19.4 & 11.6 & 18.8 & 18.5 & 19.1 & 18.8 & 19.0 & 18.7 & 19.1 & 18.8 & 18.6 & 18.7 \\
\hline $\mathrm{HC} \equiv \mathrm{CH}$ & 22.5 & 13.3 & 22.1 & 22.0 & 21.2 & 21.0 & 21.3 & 21.2 & 21.3 & 21.1 & 21.0 & 20.8 \\
\hline $\mathrm{H}_{2} \mathrm{C}=\mathrm{CH}_{2}$ & 21.3 & 10.6 & 20.9 & 20.5 & 19.6 & 19.2 & 19.8 & 19.4 & 19.9 & 19.4 & 19.2 & 19.7 \\
\hline $\mathrm{H}_{3} \mathrm{C}-\mathrm{CH}_{3}$ & 30.8 & 17.3 & 29.7 & 29.1 & 29.4 & 29.0 & 29.3 & 28.9 & 29.5 & 29.0 & 28.8 & 27.4 \\
\hline $\mathrm{H}_{2} \mathrm{C}=\mathrm{C}=\mathrm{CH}_{2}$ & 32.0 & 17.6 & 30.6 & 30.0 & 30.7 & 30.2 & 30.5 & 30.0 & 30.7 & 30.1 & 30.2 & $25.3 \pm 0.8$ \\
\hline cyclo- $\mathrm{C}_{3} \mathrm{H}_{6}$ & 43.4 & 26.6 & 42.3 & 41.4 & 41.2 & 40.5 & 41.2 & 40.5 & 41.5 & 40.7 & 40.1 & 39.9 \\
\hline $\mathrm{H}_{3} \mathrm{C}-\mathrm{CH}_{2}-\mathrm{CH}_{3}$ & 43.3 & 24.1 & 41.7 & 40.9 & 41.1 & 40.5 & 41.0 & 40.4 & 41.3 & 40.6 & 40.4 & 40.5 \\
\hline 1-Butene & 46.4 & 24.8 & 45.0 & 44.0 & 43.3 & 42.5 & 43.4 & 42.7 & 43.7 & 42.8 & 42.6 & 41.0 \\
\hline trans-2-Butene & 46.3 & 26.0 & 44.7 & 43.6 & 43.2 & 42.3 & 43.3 & 42.4 & 43.5 & 42.6 & 42.6 & 43.3 \\
\hline $\mathrm{C}_{6} \mathrm{H}_{6}$ & 62.7 & 37.7 & 60.4 & 58.9 & 55.4 & 54.2 & 56.2 & 54.9 & 56.5 & 55.1 & 54.3 & 55.0 \\
\hline cyclo- $\mathrm{C}_{6} \mathrm{H}_{12}$ & 73.5 & 49.5 & 69.9 & 68.3 & 67.8 & 66.5 & 67.8 & 66.5 & 67.1 & 68.5 & 66.4 & 68.0 \\
\hline $\mathrm{CH}_{3} \mathrm{OH}$ & 23.0 & 14.2 & 22.4 & 21.8 & 21.9 & 21.5 & 21.9 & 21.5 & 21.6 & 22.0 & 21.3 & 21.4 \\
\hline $\mathrm{CH}_{3} \mathrm{CHO}$ & 22.1 & 12.7 & 22.4 & 21.9 & 20.8 & 20.3 & 20.6 & 21.1 & 20.6 & 21.1 & 20.5 & 22.2 \\
\hline $\mathrm{CH}_{3} \mathrm{CH}_{2} \mathrm{OH}$ & 36.2 & 20.3 & 35.0 & 34.2 & 34.3 & 33.7 & 34.3 & 33.7 & 34.5 & 33.8 & 33.5 & 33.7 \\
\hline MAE & 3.300 & 12.186 & 2.071 & 1.371 & 1.121 & 1.050 & 1.164 & 0.929 & 1.350 & 0.921 & 1.000 & \\
\hline RMSE & 1.593 & 2.401 & 1.542 & 1.545 & 1.662 & 1.709 & 1.756 & 1.559 & 1.756 & 1.756 & 1.679 & \\
\hline$A$ & 0.897 & 1.334 & 0.948 & 0.973 & 1.000 & 1.021 & 0.993 & 1.021 & 0.996 & 0.997 & 1.020 & \\
\hline B & 0.579 & 4.884 & -0.181 & -0.359 & -0.857 & -0.951 & -0.672 & -1.081 & -0.842 & -0.518 & -0.867 & \\
\hline$R$ & 0.9946 & 0.9877 & 0.9950 & 0.9949 & 0.9941 & 0.9938 & 0.9944 & 0.9949 & 0.9935 & 0.9953 & 0.9940 & \\
\hline
\end{tabular}

Table 3

Calculated and experimental ${ }^{1} \mathrm{H}$ chemical shifts (in ppm) for some of hydrocarbons (relatively to $\mathrm{CH}_{4}$ ), values of MAE and RMSE, and parameters of the linear regression equation $\delta_{\text {expt }}=A \delta_{\text {calc }}+B$.

\begin{tabular}{|c|c|c|c|c|c|c|c|c|c|c|c|c|c|c|c|c|}
\hline \multirow{2}{*}{$\begin{array}{l}\text { Method } \\
\text { Basis set }{ }^{\mathrm{a}}\end{array}$} & \multicolumn{3}{|l|}{$\mathrm{HF}$} & \multicolumn{3}{|l|}{ BP86 } & \multicolumn{3}{|l|}{ B3LYP } & \multicolumn{3}{|c|}{ PBE1PBE } & \multicolumn{3}{|l|}{ MP2 } & \multirow[t]{2}{*}{ Expt. } \\
\hline & I & II & III & I & II & III & I & II & III & I & II & III & I & II & III & \\
\hline \multicolumn{17}{|l|}{ GIAO } \\
\hline $\mathrm{C}_{2} \mathrm{H}_{4}$ & 5.19 & 5.16 & 5.28 & 5.61 & 5.40 & 5.54 & 5.49 & 5.32 & 5.47 & 5.61 & 5.45 & 5.60 & 5.21 & 5.21 & 5.21 & $5.18^{c}$ \\
\hline $\mathrm{C}_{2} \mathrm{H}_{6}$ & 0.40 & 0.47 & 0.51 & 0.75 & 0.82 & 0.84 & 0.65 & 0.73 & 0.75 & 0.64 & 0.71 & 0.76 & 0.57 & 0.68 & 0.66 & $0.75^{\mathrm{c}}$ \\
\hline $\mathrm{CH}_{3} \mathrm{CH}_{2} \mathrm{CH}_{3}$ & 0.67 & 0.76 & 0.80 & 1.30 & 1.42 & 1.40 & 1.13 & 1.27 & 1.24 & 1.11 & 1.23 & 1.25 & 1.00 & 1.17 & 0.99 & $1.16^{\mathrm{c}}$ \\
\hline $\mathrm{CH}_{3} \mathrm{CH}_{2} \mathrm{CH}_{3}{ }^{\mathrm{a}}$ & 0.46 & 0.52 & 0.57 & 0.86 & 0.90 & 0.92 & 0.75 & 0.81 & 0.82 & 0.74 & 0.80 & 0.84 & 0.71 & 0.81 & 0.80 & $0.68^{c}$ \\
\hline $\mathrm{C}\left(\mathrm{CH}_{3}\right)_{4}$ & 0.37 & 0.61 & 0.33 & 0.85 & 0.94 & 0.94 & 0.70 & 0.80 & 0.80 & 0.72 & 0.82 & 0.84 & 0.73 & 0.86 & 0.82 & $0.82^{c}$ \\
\hline $\mathrm{CH}_{2}=\mathrm{CH}-\mathrm{CH}=\mathrm{CH}_{2} \mathrm{CH}_{2}$ cis & 4.90 & 5.09 & 4.89 & 5.31 & 5.19 & 5.28 & 5.19 & 5.12 & 5.21 & 5.31 & 5.23 & 5.34 & 5.02 & 5.10 & 5.07 & $4.97^{\mathrm{d}}$ \\
\hline $\mathrm{CH}_{2}$ trans & 4.79 & 4.95 & 4.73 & 5.26 & 5.13 & 5.16 & 5.13 & 5.04 & 5.07 & 5.25 & 5.15 & 5.21 & 4.92 & 4.98 & 4.93 & $4.84^{\mathrm{d}}$ \\
\hline $\mathrm{CH}$ & 6.10 & 6.21 & 6.11 & 6.56 & 6.33 & 6.53 & 6.45 & 6.26 & 6.47 & 6.54 & 6.38 & 6.59 & 6.25 & 6.20 & 6.27 & $6.21^{\mathrm{d}}$ \\
\hline cyclo- $\mathrm{C}_{6} \mathrm{H}_{12}{ }^{\mathrm{b}}$ & 0.69 & 0.79 & 0.86 & 1.40 & 1.51 & 1.55 & 1.20 & 1.32 & 1.36 & 1.20 & 1.31 & 1.39 & 1.19 & 1.36 & 1.33 & $1.31^{\mathrm{e}}$ \\
\hline MAE & 0.263 & 0.202 & 0.227 & 0.220 & 0.191 & 0.249 & 0.166 & 0.092 & 0.146 & 0.216 & 0.138 & 0.211 & 0.087 & 0.068 & 0.076 & \\
\hline RMSE & 0.132 & 0.136 & 0.137 & 0.070 & 0.075 & 0.055 & 0.076 & 0.072 & 0.051 & 0.084 & 0.074 & 0.054 & 0.068 & 0.075 & 0.087 & \\
\hline$A$ & 0.925 & 0.927 & 0.941 & 0.938 & 0.992 & 0.968 & 0.933 & 0.981 & 0.956 & 0.912 & 0.955 & 0.935 & 0.968 & 0.993 & 0.980 & \\
\hline B & 0.456 & 0.351 & 0.363 & -0.028 & -0.168 & -0.149 & 0.112 & -0.028 & -0.007 & 0.133 & 0.008 & -0.009 & 0.128 & -0.030 & 0.041 & \\
\hline$R$ & 0.9986 & 0.9985 & 0.9985 & 0.9996 & 0.9995 & 0.9998 & 0.9995 & 0.9996 & 0.9998 & 0.9994 & 0.9996 & 0.9998 & 0.9996 & 0.9996 & 0.9994 & \\
\hline \multicolumn{17}{|l|}{ CSGT } \\
\hline $\mathrm{C}_{2} \mathrm{H}_{4}$ & 5.24 & 4.36 & 5.07 & 5.62 & 4.66 & 5.36 & 5.51 & 4.55 & 4.97 & 5.65 & 4.71 & 5.42 & & & & $5.18^{\mathrm{c}}$ \\
\hline $\mathrm{C}_{2} \mathrm{H}_{6}$ & 0.35 & 0.13 & 0.39 & 0.69 & 0.44 & 0.70 & 0.60 & 0.37 & 0.31 & 0.60 & 0.37 & 0.64 & & & & $0.75^{\mathrm{c}}$ \\
\hline $\mathrm{CH}_{3} \mathrm{CH}_{2} \mathrm{CH}_{3}$ & 0.53 & 0.16 & 0.60 & 1.15 & 0.72 & 1.17 & 0.98 & 0.56 & 0.72 & 0.98 & 0.59 & 1.06 & & & & $1.16^{\mathrm{c}}$ \\
\hline $\mathrm{CH}_{3} \mathrm{CH}_{2} \mathrm{CH}_{3}^{\mathrm{a}}$ & 0.34 & 0.05 & 0.39 & 0.73 & 0.40 & 0.74 & 0.63 & 0.31 & 0.33 & 0.63 & 0.33 & 0.67 & & & & $0.68^{\mathrm{c}}$ \\
\hline $\mathrm{C}\left(\mathrm{CH}_{3}\right)_{4}$ & 0.81 & 1.59 & 0.73 & 1.14 & 1.82 & 1.30 & 1.01 & 1.70 & 1.16 & 1.05 & 1.72 & 1.20 & & & & $0.82^{\mathrm{c}}$ \\
\hline $\mathrm{CH}_{2}=\mathrm{CH}-\mathrm{CH}=\mathrm{CH}_{2} \mathrm{CH}_{2}$ cis & 5.52 & 5.70 & 5.23 & 5.72 & 5.73 & 5.61 & 5.63 & 5.67 & 5.53 & 5.78 & 5.79 & 5.66 & & & & $4.97^{\mathrm{d}}$ \\
\hline $\mathrm{CH}_{2}$ trans & 5.38 & 5.50 & 5.05 & 5.62 & 5.62 & 5.49 & 5.51 & 5.54 & 5.40 & 5.67 & 5.66 & 5.53 & & & & $4.84^{\mathrm{d}}$ \\
\hline $\mathrm{CH}$ & 6.70 & 6.60 & 6.37 & 6.93 & 6.67 & 6.78 & 6.85 & 6.60 & 6.72 & 6.99 & 6.73 & 6.84 & & & & $6.21^{\mathrm{d}}$ \\
\hline cyclo- $\mathrm{C}_{6} \mathrm{H}_{12}{ }^{\mathrm{b}}$ & 0.64 & 0.64 & 0.29 & 1.30 & 0.98 & 0.73 & 1.14 & 0.80 & 0.38 & 1.14 & 0.80 & 0.64 & & & & $1.31^{\mathrm{e}}$ \\
\hline MAE & 0.410 & 0.699 & 0.340 & 0.349 & 0.542 & 0.358 & 0.338 & 0.573 & 0.482 & 0.408 & 0.593 & 0.391 & & & & \\
\hline RMSE & 0.241 & 0.610 & 0.280 & 0.152 & 0.550 & 0.304 & 0.157 & 0.558 & 0.379 & 0.170 & 0.543 & 0.298 & & & & \\
\hline$A$ & 0.842 & 0.825 & 0.879 & 0.878 & 0.873 & 0.888 & 0.872 & 0.864 & 0.847 & 0.849 & 0.846 & 0.864 & & & & \\
\hline B & 0.495 & 0.614 & 0.525 & 0.062 & 0.258 & 0.131 & 0.180 & 0.373 & 0.479 & 0.193 & 0.369 & 0.224 & & & & \\
\hline$R$ & 0.9953 & 0.9697 & 0.9937 & 0.9982 & 0.9754 & 0.9926 & 0.9980 & 0.9747 & 0.9884 & 0.9977 & 0.9761 & 0.9928 & & & & \\
\hline
\end{tabular}

alculated as average value for all $\mathrm{CH}_{3}$ protons.

b Calculated as average value for axial and equatorial protons.

c Taken from Ref. [24].

d Obtained from chemical shifts related to TMS by subtraction 0.140 [25].

e Taken from Ref. [26]. 
slope closest to unity and the smallest intercept. It should be noted that for both extended basis sets the DFT approach offers better accuracy if compared to the HF and MP2 calculations.

High efficiency of the POLMAG-3 program for calculations of magnetic susceptibility has been shown in Ref. [16]. As could be seen from Table 2, an application of the $6-31 \mathrm{G}^{\# \#}$ basis set also significantly improves accuracy of predictions, compared to the 6$31 \mathrm{G}$ basis set at HF level of theory. The electron correlation effects at the DFT level in most cases do not make considerable impacts on the accuracy of calculations, except for highly-correlated benzene molecule.

Based on the results collected in Tables 1 and 2 one can conclude that $6-31 \mathrm{G}^{\# \#}$ basis set accurately describes the changes of electronic density caused by action of external electro-magnetic perturbation.

It should be mentioned that such magnetic properties as magnetic susceptibility and nuclear magnetic shielding, described by the following equation (for $\sigma^{p}$ as example):

$\sigma^{p} \sim \sum_{m}^{\prime} \frac{\left\langle\psi_{n}, \mathbf{L} \psi_{m}\right\rangle\left\langle\psi_{m}, \mathbf{L} r^{-3} \psi_{n}\right\rangle}{E_{n}-E_{m}}=\left\langle\psi_{n}^{(0)}, \mathbf{L} r^{-3} \psi_{n}^{(L)}\right\rangle=\left\langle\psi_{n}^{(0)}, \mathbf{L} \psi_{n}^{\left(L r^{-3}\right)}\right\rangle$

are defined by the same correction functions (10), which correspond to angular moment perturbation operator $\mathbf{L}$. Here $\left\langle\psi_{n}^{(L)}\right|=\sum_{m}^{\prime}\left(E_{n}-E_{m}\right)^{-1}\left\langle\psi_{n}, \mathbf{L} \psi_{m}\right\rangle\left\langle\psi_{m}\right|$ is the first-order correction function for $\mathbf{L}$ perturbation operator. Thus, $6-31 \mathrm{G}^{\# \#}$ basis set could be also used for calculations of nuclear magnetic shielding.

The values of ${ }^{1} \mathrm{H}$ chemical shifts for the set of hydrocarbons calculated relatively to $\mathrm{CH}_{4}$ at the HF, DFT and MP2 levels of theory are collected in Table 3 . The vibrational contributions to magnetic shieldings have not been taken into account in our calculations since, as has been shown previously in $[22,23]$, for alkyl and vinyl protons which are considered in this article, such corrections are fairly similar.

The first-order correction functions, due to magnetic field, that are depended on the coordinate of the nuclei relatively to molecular system are equal to zero at the origin point. This allows an application of the unperturbed 6-31G basis set for calculations of magnetic shielding constants at those nuclei. Based on such idea we have compared performance of "full" $6-31 G^{\# \# ~}$ basis set (I) with

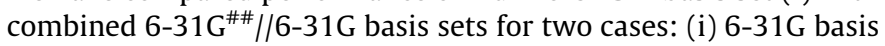
set for all hydrogen atoms and $6-31 G^{\# \#}$ - for the remaining atoms (basis set II, see legend for Table 3 ) and (ii) 6-31G basis set for the one hydrogen atom of interest and $6-31 G^{\# \#}$ - for the remaining atoms (basis set III).

The obtained results clearly demonstrate advantage of the GIAO approach over CSGT technique at both the HF and DFT levels. For GIAO/6-31G\#\# calculations an accuracy decreases in the order: $\mathrm{MP} 2>\mathrm{B} 3 \mathrm{LYP} \approx \mathrm{BP} 86 \approx \mathrm{PBE} 1 \mathrm{PBE}>\mathrm{HF}$. The largest deviations from the experimental data at the DFT level are observed for vinyl protons in ethylene and butadiene molecules. These discrepancies are reduced at the MP2 level. The MP2 data shows good agreement between calculated and observed chemical shifts, both for the alkyl and vinyl protons. As could be seen from Table 3, CSGT-DFT and CSGT-HF approaches do not allow obtaining reliable results with basis sets II and III. In contrast, GIAO-DFT and GIAO-MP2 calculations provide sufficiently reliable results for nuclear magnetic shielding with accuracy comparable, and in some cases better than those obtained from calculations using $6-31 G^{\# \#}$ basis set at the same levels of theory.

\section{Conclusions}

We have shown a good performance of the tested approach for calculations of second-order electric and magnetic properties (polarizability, magnetizability, and nuclear magnetic shielding). This technique is based on the consideration of simultaneous dependence of orbital coefficients and basis functions on an appropriate perturbation operator. The obtained correction functions could be directly implemented into the standard coupled-perturbed approach or applied for augmentation of any standard basis set. Combination of unperturbed basis set for nuclei of interest and extended basis set for the rest of atoms at GIAO-MP2 and GIAODFT levels of theory might be used as cost-effective approaches for accurate calculations of ${ }^{1} \mathrm{H}$ nuclear magnetic shielding (chemical shift).

\section{Acknowledgment}

This research was supported by the NSF Nanotoxicity CREST Center Grant No. HRD-0833178.

\section{References}

[1] R.M. Stevens, R.M. Pitzer, W. Lipscomb, J. Chem. Phys. 38 (1963) 550.

[2] W. Kutzelnigg, U. Fleischer, M. Schindler, NMR Basic Principles and Progress, vol. 23, Springer, Berlin, 1990. p. 165.

[3] F. London, Naturwissenschaften 15 (1937) 187.

[4] W. Kutzelnigg, Isr. J. Chem. 19 (1980) 193.

[5] M. Schindler, W. Kutzelnigg, J. Chem. Phys. 76 (1982) 1919

[6] A.E. Hansen, T.D. Bouman, J. Chem. Phys. 82 (1985) 5035

[7] T.A. Keith, R.H.W. Bader, Chem. Phys. Lett. 194 (1992) 1.

[8] T.A. Keith, R.H.W. Bader, Chem. Phys. Lett. 210 (1993) 223.

[9] V.G. Malkin, O.L. Malkina, L.A. Eriksson, D.R. Salahub, in: J.M. Seminario, P. Poliytzer (Eds.), Modern Density Functional Theory, Theoretical and Computational Chemistry, vol. 2, Elsevier Science, New York, 1995, p. 273.

[10] M. Kollwitz, J. Gauss, Chem. Phys. Lett. 260 (1996) 639.

[11] M. Kollwitz, M. Haser, J. Gauss, J. Chem. Phys. 108 (1998) 8295

[12] T. Helgaker, M. Jaszunski, K. Ruud, Chem. Rev. 99 (1999) 293.

[13] A.B. Bolotin, V.V. Rossikhin, E.O. Voronkov, Acta Phys. Hung. 70 (1991) 299.

[14] E.T. Whittaker, Bull. Am. Math. Soc. 10 (1904) 125.

[15] V.V. Rossikhin, E.O. Voronkov, S.I. Okovytyy, L.I. Shapovalov, SITA 2 (2000) 35.

[16] S.I. Okovytyy, E.O. Voronkov, V.V. Rossikhin, O.K. Balalayev, J. Leszczynski, J. Phys. Chem. A 108 (2004) 4930.

[17] V.V. Rossikhin, V.V. Kuz'menko, E.O. Voronkov, J. Phys. Chem. 100 (1996) 19801.

[18] V.V. Rossikhin, S.I. Okovytyy, L.I. Kasyan, E.O. Voronkov, L.K. Umrikhina, J. Leszczynski, J. Phys. Chem. A 106 (2002) 4176.

[19] M.J. Frisch, G.W. Trucks, H.B. Schlegel, G.E. Scuseria, M.A. Robb, J.R. Cheeseman, V.G. Zakrzewski, J.A. Montgomery Jr., R.E. Stratmann, J.C. Burant, S. Dapprich, J.M. Millam, A.D. Daniels, K.N. Kudin, M.C. Strain, O. Farkas, J. Tomasi, V. Barone, M. Cossi, R. Cammi, B. Mennucci, C. Pomelli, C. Adamo, S. Clifford, J. Ochterski, G.A. Petersson, P.Y. Ayala, Q. Cui, K. Morokuma, D.K. Malick, A.D. Rabuck, K. Raghavachari, J.B. Foresman, J. Cioslowski, J.V. Ortiz, A.G. Baboul, B.B. Stefanov, G. Liu, A. Liashenko, P. Piskorz, I. Komaromi, R. Gomperts, R.L. Martin, D.J. Fox, T. Keith, M.A. Al-Laham, C.Y. Peng, A. Nanayakkara, C. Gonzalez, M. Challacombe, P.M.W. Gill, B. Johnson, W. Chen, M.W. Wong, J.L. Andres, C. Gonzalez, M. Head-Gordon, E.S. Replogle, J.A. Pople, Gaussian 98, Revision A.11, Gaussian, Inc., Pittsburgh, PA, 1998.

[20] D. Russell (Ed.) NIST Computational Chemistry Comparison and Benchmark Database, NIST Standard Reference Database Number 101 Release 14, September 2006, Johnson III. <http://srdata.nist.gov/cccbdb>.

[21] D.R. Lide, (Ed.), CRC Handbook of Chemistry and Physics, 89th ed., CRC Press/ Taylor and Francis, Boca Raton, FL.

[22] D.B. Chesnut, Chem. Phys. 214 (1997) 73.

[23] K. Ruud, P.-O. Åstrand, P.R. Taylor, J. Am. Chem. Soc. 123 (2001) 4826

[24] M. Schindler, W. Kutzelnigg, J. Am. Chem. Soc. 105 (1983) 1360.

[25] T. Zuschneid, H. Fischer, T. Handel, K. Albert, G.Z. Häfelinger, Naturforsch. 59b (2004) 1153.

[26] E.W. Garbisch, M.G. Griffith, J. Am. Chem. Soc. 90 (1968) 6543. 